Note

\title{
Growth Inhibitory Effect of Shelf Life Extending Agents on Bacillus subtilis IAM 1026
}

\author{
SAORI MITSUBOSHI ${ }^{*}$, RIE OBITSU ${ }^{1}$, KANAKO MURAMATSU ${ }^{2}$, \\ KENTARO FURUBE ${ }^{3}$, SHIGEHIRO YOSHITAKE ${ }^{3}$, AND KAN KIUCHI ${ }^{1}$ \\ 'Faculty of Home Economics, Kyoritsu women's University, \\ 2-2-1 Hitotsubashi, Chiyoda-ku, Tokyo 103-8437, Japan \\ ${ }^{2}$ Department of Human Life and Environmental Science, Niigata Women's College, \\ 471 Ebigase, Higashi-ku, Niigatashi, Niigata 950-8680, Japan \\ ${ }^{3}$ Eisai Food \& Chemical Co. Ltd., 5th Floor Nihonbashi-Sunrise-Building, \\ 2-13-10 Nihonbashi, Chuo-ku, Tokyo 103-0027, Japan
}

Received 15 June, 2006/Accepted 4 February, 2007

\begin{abstract}
Natural shelf life extending agents and sugar fatty acid esters that might inhibit the growth of $B$. subtilis IAM 1026 were screened, and the effective agents were as follows: $\beta$-thujaplicin (Hinokitiol) and chitosan, inhibited the growth of IAM 1026 at a concentration of $0.001 \% ; \varepsilon$ polylysine and $\mathrm{M}-1695$ (a sugar fatty acid ester) at $0.005 \%$; citrus seed extract, thiamin lauryl sulfate, and grapefruit seed extract at 0.01\%; CT-1695 and L-1695 (sugar fatty acid esters) at $0.05 \%$; pectin digests and SM-800 (a sugar fatty acid ester) at $0.5 \%$; water pepper seed extract and the sugar fatty acid esters SM-1000 and CE-1695 at 1.0\%. The growth inhibitory effects of the agents in custard cream were not necessarily similar to those in liquid culture. The agent that showed the highest inhibitory effect in custard cream was $0.3 \% \beta$-thujaplicin, followed by $0.3 \% \varepsilon$-polylysine.
\end{abstract}

Key words: Bacillus subtilis IAM 1026/Growth inhibitory effect of natural shelf life extending agents and sugar fatty acid esters/Growth inhibition in liquid culture and custard cream.

Current trends toward decreasing the salt and sugar content of foods, as well as the development of new types of food products, have made food preservation increasingly challenging (Katsumata et al., 2004; Takahashi et al., 2005; Kanai and Aida, 2006). The use of preservation agents other than salt and sugar has become increasingly important, but consumer resistance to the use of synthetic food additives has limited food manufacturers' choice of preservatives. Thus, new, more sophisticated techniques are needed for the management of food hygiene and preservation.

In this study, we screened various natural food additives and emulsifiers for bacteriostatic effects against $B$. subtilis IAM 1026 (abbreviated as IAM

${ }^{*}$ Corresponding author. Tel: $+81-3-3237-2483, \mathrm{Fax}:+81$ 3-3237-2688.
1026 hereafter) and compared their growth inhibitory effects against IAM 1026 inoculated into two systems: a liquid culture medium and custard cream. The $\mathrm{pH}$ of the nutrient broth (Difco, NB medium) was adjusted to 7.0 after food additives were added. A loopful of bacterial cells was inoculated into $10 \mathrm{ml}$ of nutrient broth and cultured by shaking reciprocally at $30^{\circ} \mathrm{C}$ for $24 \mathrm{~h}$. The cultured medium $(0.1 \%)$ was newly inoculated into $10 \mathrm{ml}$ of NB medium and cultured by shaking reciprocally at $30^{\circ} \mathrm{C}$.

The shelf life extending agents (Japan Food Additives Association, 1999) used were grapefruit seed extract (Daiichi Chemicals, abbreviated as GF), chitosan (Taiyo Chemical Industry, Co., Ltd.; Deacetylation degree, 85\%), pectin digests (Asama Chemicals, trade name Noipectin- $L$, consisting of pectin digests at $28 \%$, lactic acid at $14 \%$, other food materials at 58\%), citrus seed extract (Morita Foods, 
abbreviated as citrus), $\beta$-thujaplicin (trade name Hinokitiol, Seiwa Chemicals), water pepper seed extract (Sanyo Fine Chemicals, abbreviated as water pepper), thiamin lauryl sulfate (trade name Vitagen AS5, Tanabe Seiyaku, abbreviated as thiamin), and $\varepsilon$-polylysine (Chisso, $50 \%$ content, abbreviated as polylysine). The emulsifiers used were sugar fatty acid esters (Mitsubishi Chemical Foods, trade name Ryo-to Sugar Ester), L-1695, CE-1695, M-1695, CT1695, SM-800, and SM-1000.

Growth in NB medium was assessed by absorbance at $660 \mathrm{~nm}$ by Mini Photo (Taitec Co.) and calculated as follows: The growth ratio is the percentage ratio of growth in the presence of a shelf life extending agent or emulsifier to the growth in the absence of that agent. Thus, the growth ratio (\%) of IAM $1026=$

Growth when a shelf life extending agent or emulsifier is added $\left(0 D_{600}\right)$

Growth when a shelf life extending agent or emulsifier is not added $\left(0 D_{600}\right) \times 100$

The criteria for judging the growth ratio (\%) and growth inhibitory effect $(-$ to ++++$)$ were as follows: Growth ratio $0 \%=$ growth inhibitory effect $++++; 0 \% \sim<10 \%\left(4.70 \times 10^{7} \mathrm{cfu} / \mathrm{ml}\right),+++$; $10 \% \sim<40 \% \quad\left(1.88 \times 10^{8} \mathrm{cfu} / \mathrm{ml}\right), \quad++$; $40 \% \sim<60 \%\left(2.82 \times 10^{8} \mathrm{cfu} / \mathrm{ml}\right),+; 60 \% \sim 90 \%$ $\left(4.23 \times 10^{8} \mathrm{cfu} / \mathrm{ml}\right), \pm ; 90 \% \sim<100 \%\left(4.70 \times 10^{8}\right.$ $\mathrm{cfu} / \mathrm{ml}),-$. Therefore, the smaller the growth ratio, the greater the inhibitory effect.

Preparation was performed according to the methods reported previously (Osawa et al., 1998).

Some agents promoted growth of IAM 1026 when present in low concentrations but inhibited growth when present at high concentrations in liquid culture. At low concentrations, these agents or their metabolic derivatives may serve as nutrients for $B$. subtilis. Fig. 1 shows the growth of IAM 1026 when GF, water pep- per, polylysine, chitosan, or $\beta$-thujaplicin was added. The growth ratio with $0.005 \%$ GF reached $171.2 \%$ at $24 \mathrm{~h}$ but decreased slightly at later time points (Fig. $1 \mathrm{~A})$. However, the growth ratio was $3.0 \%$ at $48 \mathrm{~h}$ when $0.01 \%$ GF was added, and the inhibitory effect with $0.1 \%$ was +++ . Addition of thiamin at the $0.005 \%$ level produced an $83.3 \%$ growth ratio, with a $103.7 \%$ growth ratio at $72 \mathrm{~h}$ (data not shown). With $0.01 \%$ thiamin, no growth was observed, which meant that the growth inhibitory effect was ++++ . Some agents showed a growth inhibitory effect at high concentrations but did not promote growth at low concentrations (Fig. 1B). Citrus is an example. The addition of $0.001 \%$ citrus inhibited growth at 24 $\mathrm{h}$, but regrowth was observed at $48 \mathrm{~h}$, and the growth ratio reached to $98.1 \%$ at $72 \mathrm{~h}$ (data not shown). $0.1 \%$ and $0.5 \%$ of water pepper inhibited growth for $48 \mathrm{~h}$, but the growth ratios reached $45.0 \%$ and $48.0 \%$, respectively, at $72 \mathrm{~h}$. At a $1.0 \%$ concentration, water pepper completely inhibited growth. The growth inhibitory effect of water pepper seemed weaker than the effects of pectin digests, GF, or thiamin. Growth was inhibited almost completely by $0.005 \%$ polylysine, $0.001 \%$ chitosan, and $0.001 \%$ $\beta$-thujaplicin; thus, their growth inhibitory effects were ++++ (Fig. 1C). These three shelf life extending agents were not degraded to nutrients and thus could exert strong bacteriostatic effects at low concentrations.

Addition of $0.1 \%$ SM-800 led to a high growth ratio of $143.0 \%$ at $48 \mathrm{~h}$, and $0.05 \% \mathrm{SM}-1000$ produced a $231.0 \%$ growth ratio at $24 \mathrm{~h}$ (Fig. $2 \mathrm{~A}$ ). At these concentrations, both of these substances failed to inhibit the growth of IAM 1026 at later time points. Concentrations of $0.5 \%$ or higher of SM- 800 inhibited growth completely. A concentration of $0.1 \%$ of SM-
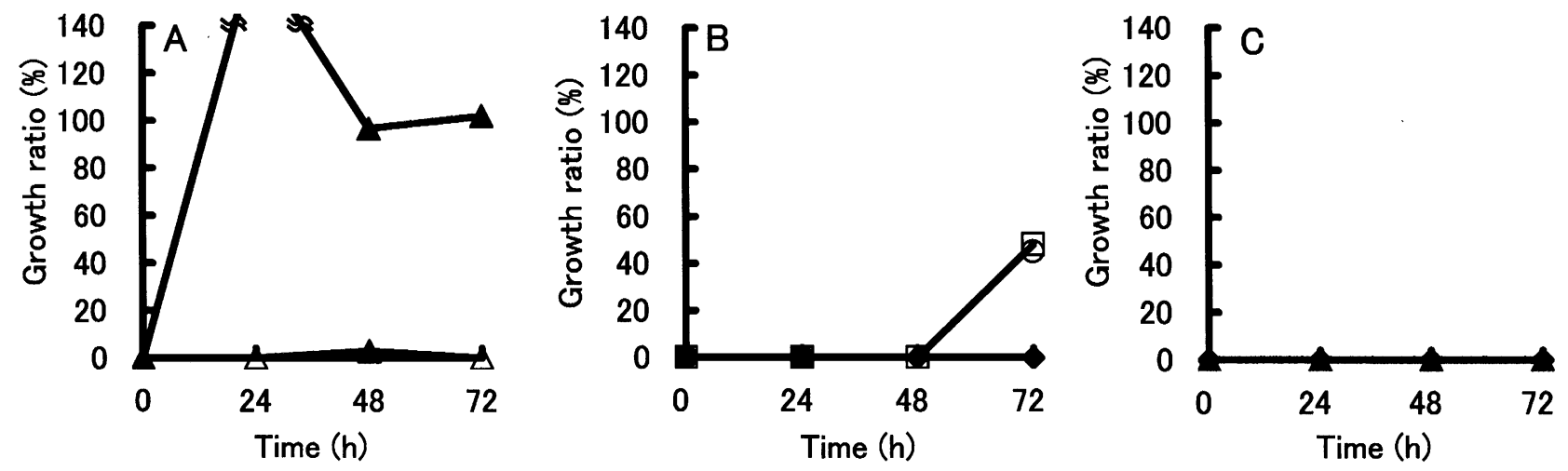

FIG. 1. The growth of Bacillus subtilis IAM 1026 with the addition of GF, water pepper, polylysine, chitosan, or $\beta$-thujaplicin.

(A), GF, $\boldsymbol{\Delta}, 0.005 \% ; \triangle, 0.01 \%$ : (B), water pepper; $\bigcirc, 0.1 \% ; \square, 0.5 \% ; \diamond, 1.0 \%$ : (C), polylysine, $\boldsymbol{\Delta}, 0.005 \%$; chitosan, $\triangle, 0.001 \% ; \beta$-thujaplicin,, $0.01 \%$. 
1000 did not inhibit growth at $72 \mathrm{~h}$, but growth was completely inhibited by a $1.0 \%$ concentration of the same substance. Since those two sugar esters contained capric or caprylic acid at $99 \%$ concentration, they might act as nutrients at low concentrations.

As shown in Fig. 2B, the growth ratio was less than $10 \%$ at a $0.05 \%$ or higher concentration of CT- 1695 and the growth ratio was 62 to $69 \%$ between 24 and $72 \mathrm{~h}$ after $0.5 \%$ addition of CE-1695 (data not shown).

Fig. 3 shows sugar fatty acid esters that had a high growth inhibitory effect. A $0.005 \%$ addition of M-1695 produced a growth ratio of less than $3.0 \%$, and the growth inhibitory effect was +++ (Fig. 3A). A $0.05 \%$ or higher concentration of L- 1695 produced a growth ratio of less than $3.0 \%$, with a growth inhibitory effect of +++ (Fig. 3B).

In some instances, shelf life extending agents with growth inhibitory effects in liquid media do not have as great an effect when added to foods at the same concentrations (Katsumata et al., 2003a, b; Katsumata et al. 2004). The growth inhibitory effects of shelf life extending agents in liquid culture were investigated by adding them to custard cream at 0.1 to $1.0 \%$. The sugar fatty acid esters were completely ineffective in custard cream, with no growth inhibitory effect even at a $1.0 \%$ concentration.

The growth inhibitory effects of chitosan, $\beta$ thujaplicin, water pepper, and polylysine in custard cream were investigated. When $\beta$.-thujaplicin was added at $0.1 \%$, the growth ratio of IAM 1026 was $11.1 \%$ (growth inhibitory effect ++ ) at $48 \mathrm{~h}$ and $21.7 \%(++)$ at $72 \mathrm{~h}$, which was insufficient to prevent putrefaction. As shown in Table 1, 0.3\% $\beta$ thujaplicin inhibited growth completely.

Polylysine, at a concentration of $0.3 \%$, decreased
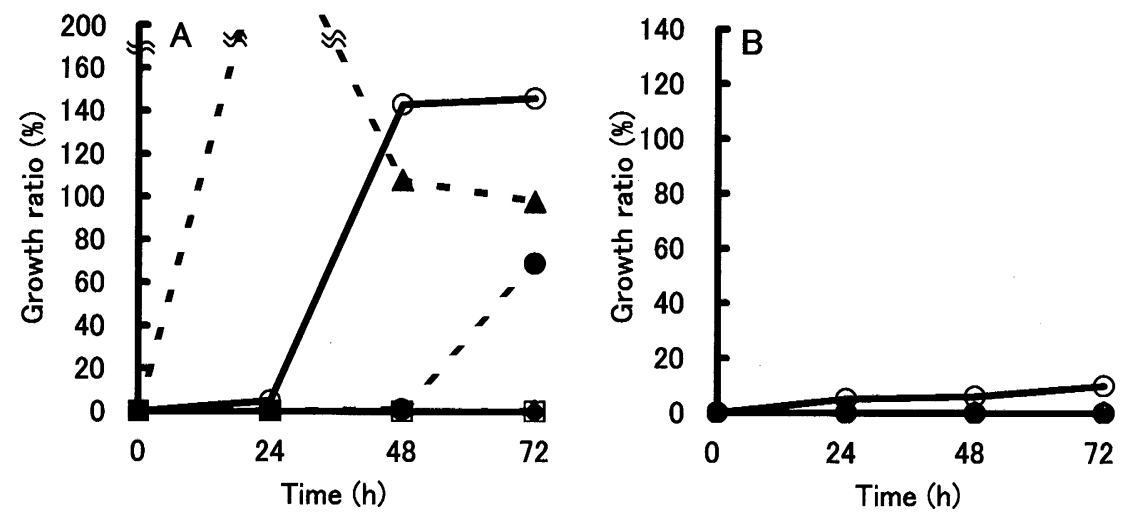

FIG. 2. The growth of Bacillus subtilis IAM1026 with the addition of SM-800, SM1000 and CT-1695.

(A), SM-800, O, 0.1\%; $\square, 0.5 \%:$ SM-1000, A. $0.05 \%$;, $0.1 \% ; \bullet, 1.0 \%$. (B), CT$1695,0.05 \% ; \bigcirc, 0.1 \% ;>1.0 \%$
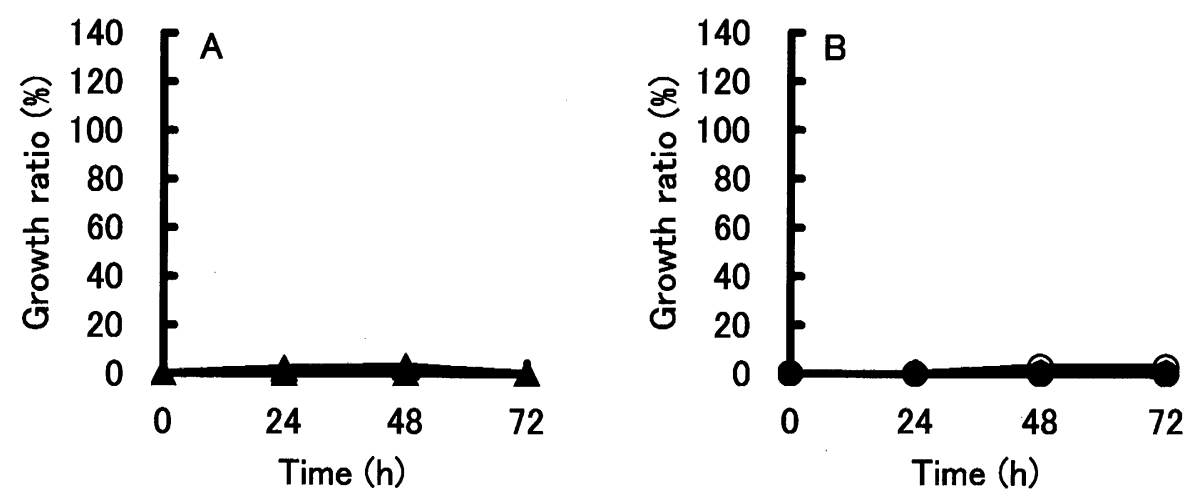

FIG. 3. The growth of Bacillus subtilis IAM 1026 with the addition of M-1695 and L1695.

(A), M-1695, $\Delta, 0.005 \% ; \triangle, 0.01 \%$ (B), L-1695, O, 0.05\%; O, $0.1 \%$ 
TABLE 1. Growth inhibitory effect of shelf life extending agents in custard cream.

\begin{tabular}{|c|c|c|c|c|c|c|c|c|}
\hline \multirow{3}{*}{$\begin{array}{l}\text { Shelf life } \\
\text { extending } \\
\text { agents }\end{array}$} & \multicolumn{8}{|c|}{ Concentration } \\
\hline & \multicolumn{2}{|c|}{$0.1 \%$} & \multicolumn{2}{|c|}{$0.3 \%$} & \multicolumn{2}{|c|}{$0.5 \%$} & \multicolumn{2}{|c|}{$1.0 \%$} \\
\hline & $48 \mathrm{~h}$ & $72 \mathrm{~h}$ & $48 \mathrm{~h}$ & $72 \mathrm{~h}$ & $48 \mathrm{~h}$ & $72 \mathrm{~h}$ & $48 \mathrm{~h}$ & $72 \mathrm{~h}$ \\
\hline Chitosan & ++ & \pm & & & +++ & - & ++++ & ++++ \\
\hline$\beta$-Thujaplicin & ++ & ++ & +++ & ++++ & +++ & +++ & ++++ & +++ \\
\hline Water pepper & \pm & + & & & + & - & ++++ & ++++ \\
\hline Polylysine & \pm & - & ++ & +++ & +++ & ++++ & ++++ & ++++ \\
\hline
\end{tabular}

See the accompanying report for an explanation of the symbols.

the growth ratio to $26.3 \%$ at 48 hours $(++)$ and $1.1 \%$ at $72 \mathrm{~h}(+++)$. A $0.5 \%$ addition of polylysine decreased it to $1.3 \%(+++)$ at $48 \mathrm{~h}$ and $0.0 \%$ at 72 $\mathrm{h}(++++)$.

The growth ratio was higher than $100.0 \%$ when $0.5 \%$ of chitosan or water pepper was added, indicating that neither of these agents was suitable for use as a growth inhibitor at this concentration. Our results indicate that the greatest growth inhibitory effects were shown with $\beta$-thujaplicin and chitosan in liquid culture and with $\beta$-thujaplicin and polylysine in custard cream.

Putrefaction with $B$. subtilis can cause an unpleasant odor as had occurred in the putrefied custard cream in this study. We searched for natural food additives and emulsifiers that could act as shelf life extending agents to inhibit the growth of IAM 1026 at $30^{\circ} \mathrm{C}$ for a few days. The agents that we studied required higher concentrations to exert a growth inhibitory effect in custard cream than in a liquid medium. Kanai (1991) has reported similar results. Some agents that were effective in liquid culture were ineffective in custard cream. Thus, the effectiveness of a growth inhibitor in liquid culture may be only a rough indicator of its effectiveness in foods. The most effective shelf life extending agents in liquid culture in our study were $\beta$-thujaplicin and chitosan, which showed complete growth inhibition of IAM 1026 at a concentration of $0.001 \%$. Since $\beta$-thujaplicin emits a unique strong flavor, it should be used without coming into direct contact with the target foods, for example in the covering film, and it should be removed by vaporization before using the foods. Shelf life extending agents other than $\beta$-thujaplicin did not emit strong flavors. However, sugar fatty acid esters are acrid, and care should therefore be taken when using them. Some shelf life extending agents, such as pectin digests, GF, and thiamin, and sugar fatty acid esters, such as SM-800 and SM-1000, promote growth of IAM 1026 at low concentrations. Addition of such levels of these substances to foods should be avoided if a growth inhibitory effect is desired. In the many foods that can be putrefied by $B$. subtilis like IAM
1026, shelf life could be extended by using some of the agents investigated here.

\section{ACKNOWLEDGEMENTS}

The authors thank Miss Ikuyo Koyama and Miss Sumi Nishiuchi for their help in the experiments. They also express thanks to Mr. Takashi Kaji and Mr. Masamoto Tomabeti, Section of Market Development, Mitsubishi Chemical Foods Co. Ltd. (Tokyo), for their gift of sugar fatty acid esters.

\section{REFERENCES}

Claus, D. and Berkeley, R. C. W. (1986) Genus Bacillus Cohn 1872 BL Bergey's Manual of Systematic Bacteriology, Vol. 2, Ed. by Sneath, P. H. A., Mair, N. S., Sharpe, M. E. and Holt, J. G., Williams \& Wilkins (Baltimore, U.S.A.), pp.1104-1139.

Kanai, M. (1991) Antibacterial effect of ovolysozyme in combination with ethanol and sodium polyphosphate on Bacillus subtilis (in Japanese), J. Antibact. Antifung. Agents, 9, 119-125.

Katsumata, R., Nakamura, Y., Oomori, Y., Yamaguchi, T., Muramatsu, K., Furube, K., Yoshitake, S. and Kiuchi, K. (2003a) Growth inhibitory effects of natural shelf life extending agents against Lactobacillus spp. (in Japanese) Bokin Bobai, 31, 301-310.

Katsumata, R., Nakamura, Y., Izumi, Y., Sakurai, H. Nishimura, M., Furube, K., Yoshitake, S. and Kiuchi, K. (2003b) Growth inhibitory effects of natural shelf life extending agents against Leuconostoc spp. (in Japanese), Bokin Bobai, 31, 311-318.

Katsumata, R., Takahashi, S., Furukawa, K., Furube, K., Yoshitake, S. and Kiuchi, K. (2004) Growth inhibition of putrefactive lactic acid bacteria, Streptococci, by natural shelf life extending agents (in Japanese), Bokin Bobai, 32, 53-61.

Japan Food Additives Association (1999) List on Existing Food Additives (in Japanese). In Annotation Book of Existing Food Additives' List on Existing Food Additives, pp.207-519, Japan Food Additives Association, Tokyo.

Osawa, S., Endo, M., Nagasaki, Y., Muramatsu, K., Hidaka, Y., Furube, K. and Kiuchi, K. (1998) Growth inhibition of putrefactive lactic acid bacteria, Leuconostoc sp. histidine. Biocontrol Sci, 3, 73-77.

Smith, N. R. and Gordon, R. E. (1976) The Genus Bacillus, Bergey's Manual of Determinative Bacteriology, 7th ed. by Breed, R. S., Murray, E. G. D. and Smith, N. R. pp.613634 , The Williams \& Wilkins Company, Baltimore, U.S.A. Takahashi, S., Katsumata, R. Kikoku, Y. and Kiuchi, K. 
(2005) Grwoth inhibition of jam putrefactive fungi by furfral (in Japanese), Bokin Bobai, 33, 579-588. 